\title{
Effects of knowledge management on client-vendor relationship quality: the mediating role of global mindset
}

\begin{abstract}
Purpose - This study argues that knowledge management by itself has only limited effects on client-vendor relationship of global providers of highly customised services. Rather it is the ability of top management to properly evaluate and utilise a vast array of complex knowledge which allows global firms to develop and maintain superior client-vendor relationship. The paper tests the proposition that global mindset of top management mediates the effects of knowledge management on client-vendor relationship quality.
\end{abstract}

Design/methodology/approach - The paper uses survey data from a sample of 68 international service providers (ISPs) in the information technology sector in India and partial least squares approach to structural equation modelling in order to test the hypotheses.

Findings - The results show that both knowledge management and global mindset have positive and statistically significant effects on the quality of client-vendor relationships. The results also confirm that the global mindset of top management has significant and substantive mediation effects on the relationship between knowledge management and client-vendor relationship quality.

Research limitations/implications - The small size of the sample and the focus on ISPs in a single country constitute the main limitations of the study. Future research should ideally draw from a larger sample of ISPs from multiple countries and sectors in order to allow for greater generalization of the findings.

Practical implications - ISPs will benefit from developing the global mindset of their top management teams in order to enhance their client-vendor relationships.

Originality/Value - The paper provides new insights into how in an international context, firms can transform their knowledge management into superior client-vendor relationship quality through the development of global mindset.

Keywords: Knowledge management, Global mindset, Client-vendor relationships, Outsourcing, International service provider, India.

\section{Paper Type - Research paper}

This is the final version of the paper accepted by the journal Please cite this paper as Sharma, R. R., Chadee, D., \& Roxas, B. (2016). Effects of knowledge management on client-vendor relationship quality: The mediating role of global mindset. Journal of Knowledge Management, 20(6), 1268-1281, doi:http://dx.doi.org/10.1108/JKM-03-2016-0099.

Published paper available at: http://dx.doi.org/10.1108/JKM-03-2016-0099 


\section{Introduction}

The role of client-vendor relationships has been identified as a critical factor in influencing the performance of firms in general and for service providers in particular. This is because effective relationships allow business partners to leverage each other's resources and learn from each other (Kale et al., 2000; Mathews, 2006). The development and maintenance of effective relationships is more critical in the services sector due to the intangibility, inseparability, heterogeneity and perishability of services (Zeithaml et al., 1985). The very nature of the tasks involved in services means that service providers and their clients work closely with each other and share sensitive information about their businesses. Inevitably, service providers often become integral parts of the value chain of their clients where the success of a client and its service provider are intertwined as the latter's failure is likely to affect the client adversely. Good quality relationships between service providers and their clients greatly reduce the risks of failure in the delivery of high quality customised services to clients a (Kedia and Lahiri, 2007; Leal-Millan et al., 2016; Raman et al., 2013). Thus, a critical element of success for service providers is their ability to manage knowledge from their clients effectively by developing and maintaining high quality relationships with them.

Knowledge management for the development and maintenance of effective client-vendor relationships (CVR) is particularly challenging for international service providers (ISPs). This is because ISPs often operate in multiple locations with different cultures, languages and institutions simultaneously. Managing knowledge in such a complex environment is even more challenging for ISPs from developing and emerging economies because of the inherent disadvantages they face by virtue of their country of origin (Denk et al., 2012; Ramachandran and Pant 2010). ISPs have been found to overcome their capability and capacity constraints (Ramachandran and Pant, 2010) by developing high quality relationships which allow them gain access to valuable knowledge and resources of their clients (Mathews, 2006). Thus, for ISPs, the capability of top management to successfully navigate through diverse cultural and institutional environments and manage a vast array of knowledge about markets, products and services is critical in developing and maintaining effective client-vendor relationships. This capability which is broadly referred to as the global mindset relates to the superior cognitive capability of senior managers to relate to diverse cultural and institutional environments (Javidan and Bowen, 2013; Levy et al., 2007) in identifying and exploiting business opportunities in an increasingly globalised world. 
The main contention of this research is that while knowledge management is important for maintaining effective relationships between ISPs and their clients, by itself it has limited influence on relationship quality for ISPs. The paper argues that the global mindset of top management is a critical mediating factor which transforms the effects of knowledge management into quality relationships between ISPs and their clients. We draw from the dynamic capabilities theory (Teece, 2014) to argue that in globally oriented firms, global mindset serves as the mechanism which enhances the effects of knowledge management on client-vendor relationship.

This paper makes two key contributions. Firstly, the study provides empirical support for the critical role of global mindset in enhancing the effects of knowledge management on clientvendor relationship. This is an important contribution because the interplay between knowledge management and global mindset has not been fully explored to date. Secondly, by drawing from the experience of a sample of ISPs in India, the study enhances our understanding of knowledge management practices of ISPs from developing and emerging economies which are relatively less understood.

\section{Literature review and conceptual model}

The three constructs of interest in this study, namely knowledge management (KM), global mindset (GM) and client-vendor relationships (CVR) are dynamic capabilities of ISPs. These capabilities can be developed, integrated, reconfigured and redeployed in order to meet the changing and diverse business environments in which ISPs operate (Teece, 2014). ISPs that have successfully developed and leveraged these dynamic capabilities are more competitive in responding to changes in their global business environments. In this study, we offer more nuanced explanations on how KM enhances CVR through the mediating role of GM.

\section{Client-vendor relationship quality $(C V R)$}

ISPs are people-based knowledge-intensive firms where relationships are critical in servicing clients from different countries. Good client-vendor relationships allow ISPs to provide high quality services by leveraging advantages related to relational capital, co-specialization and mutual learning (Kale et al., 2000; Lahiri and Kedia, 2009). Doing business across national boundaries involves additional complexities related to different institutions, cultures and languages (Klafke et al., 2016). Developing strong relational capital often helps overcome such barriers (Peng et al., 2009) particularly in the provision of highly customised technical services 
which require service providers to have a deep understanding of their clients' businesses. ISPs often work on their clients' premises for an extended period of time and have access to sensitive information. In such an environment good client-vendor relationship based on a high level of trust on both sides helps improve the quality and speed of service delivery.

Client-vendor relationships (CVR) have been found to allow alliance partners to lower transaction costs and extract economic efficiency through the synergistic combination of assets, knowledge and capabilities (Dyer and Singh, 1998). High quality relationships with business partners are a good source of local learning and networking and lead to positive organisational outcomes ( $\mathrm{Yu}$ and Sharma, 2016). Recent evidence confirms that such relationships also enhance the performance of ISPs (Lahiri and Kedia, 2009; Raman et al., 2013). Good quality relationships have been found to increase the value of mutual ventures by at least $15 \%$ through enhanced innovations (Enlow and Ertel, 2006), client satisfaction and service delivery, and through synergistic utilisation of mutual resources (Ata and Toker, 2012; Enlow and Ertel, 2006).

\section{Knowledge management (KM)}

Knowledge is a strategic organisational resource which can be a source of sustainable competitive advantage. The knowledge-based view (KBV) of the firm suggests that knowledge, especially those that are tacit in nature is a sustainable basis for competitive advantage because these are likely to be rare, inimitable, and non-substitutable (Barney et al., 2001; Grant, 1996; Kogut and Zander, 1992). Tacit knowledge resides with individuals from both within and outside the organisation, has no explicit form, is unique to the firm, and embedded in complex processes and routines within the firm. The implicit, unarticulated and ambiguous nature of tacit knowledge prohibits immediate replication or duplication by competitors and, as such, can constitute a powerful source of competitive advantage (Kogut and Zander, 1992; Wang and Han, 2011). A main tenet of KM is that firms need to develop their capability to search, acquire, create, organise, share and transform knowledge towards the identification and exploitation of competitive advantage.

Although knowledge management has been found to generally enhance organisational outcomes (Lin, 2015; Zack et al., 2009), research specific to the effects of KM on CVR remains underdeveloped and scant. Tseng (2014) finds that supplier relationship management partially mediates the association between knowledge management capability and the performance of large Taiwanese corporations. They found that knowledge management enhances CVR 
because information and knowledge sharing improves mutual trust and collaborative efforts in meeting operational challenges. Similarly, Holzweber et al. (2012) argue that in knowledge intensive firms such as ISPs, clients and vendors co-create products and services which can only be successfully achieved in the presence of strong relationships based on trust. Along similar lines, effective knowledge management has been found to improve overall client satisfaction (Ku and Fan, 2009) which in turn results in stronger client-vendor relationships.

Knowledge management, particularly the capability of ISPs to acquire, absorb and exploit knowledge also plays a key role in the development of the global mindset (GM) of top management teams (TMTs). Knowledge management enhances learning in organisations and assists TMTs in improving their capacity to relate effectively to the global business environment. An organisation's superior capability for identifying and seeking relevant knowledge about industry trends, competition, socio-economic and cultural factors that characterise its foreign markets is often related to a globally-orientated mental predisposition of its TMTs. Thus, the global mindset of TMTs forms part of the dynamic capability which ISP's can leverage to adapt more effectively to the external business environments and respond proactively to the unique and diverse needs of clients globally ( $\mathrm{Ku}$ and Fan, 2009; Tseng 2014). The discussion above leads to the following hypotheses

$H_{1}$ : Knowledge management (KM) contributes positively to the overall quality of clientvendor relationship $(C V R)$ in ISPS.

$\mathrm{H}_{2}$ : Knowledge management (KM) contributes positively to the global mindset (GM) of top management of ISPs.

\section{Global mindset (GM)}

Substantive research in conceptualising and defining global mindset can be narrowed down to the works of Levy et al. (2007), Story and Barbuto (2011), and Javidan and Bowen (2013). Levy et al. (2007) define global mindset as a highly complex cognitive structure (p. 244) which enables managers to have an open mind about cultural, institutional and strategic complexities of an increasingly globalised world and their ability to harness such diversity effectively. Building on this conceptualisation, Javidan and Bowen (2013) describe global mindset as "the capability to influence others unlike oneself and is critical to global leader effectiveness" (p. 147). Accordingly, global mindset comprises three dimensions, namely the cognitive dimension - global intellectual capital, the affective dimension - global psychological capital, and the behavioural dimension - global social capital (Javidan and Bowen, 2013; Javidan and Walker 2012). 
Story and Barbuto (2011) argue that most of the extant literature on global mindset revolves primarily around cultural intelligence and global business orientation. They posit that managers with global mindset have high global business orientation and high cultural intelligence. Though many times studies have also used global mindset and cultural intelligence interchangeably, the two are distinctively different concepts with global mindset being a broader concept which includes cultural intelligence (Story et al., 2014). Managers with welldeveloped global mindset are necessarily culturally intelligent while culturally intelligent managers do not necessarily have a well-developed global mindset.

For the purposes of this paper, GM refers to the degree of top managers' familiarity with broad global, cultural and economic environments (Chadee et al., 2011). This conceptualisation incorporates elements of global mindset from Levy et al. (2007), Story and Barbuto (2011), and Javidan and Bowen (2013) in the sense that it takes into consideration both the cultural and strategic business orientations of global mindset. Cross cultural familiarity enables managers to understand situations using their multiple cultural lenses in making appropriate decisions in those situations (Nardon and Steers, 2008). Conversely, a lack of cultural awareness and appreciation has been found to have a negative influence on the success of international outsourcing projects (Winkler et al., 2008). ISPs usually provide services to clients in multiple countries and cultures. Thus, an appreciation of other cultures is crucial in developing and maintaining good relationships with clients.

TMTs with well-developed global mindset are also more effective in performing roles such as managing ambiguity and uncertainty, leading culturally diverse teams and coordinating people and processes across cultures and countries (Story and Barbuto, 2011). Managers with welldeveloped global mindset have the ability to collaborate and work well with people from other cultures, integrate diverse perspectives and develop trusted relationships (Javidan and Bowen, 2013; Story and Barbuto, 2011). Managers who have high levels of awareness, sensitivity and appreciation of global issues and cultural differences are more likely to gain a better understanding of the external business environment and their client's needs. Such understanding and appreciation are likely to lead to better client-vendor relationship. Hence the following hypothesis:

$H_{3}$ : The global mindset (GM) of top management contributes positively to the quality of client-vendor relationship $(C V R)$ in ISPs. 


\section{Mediation effects of global mindset}

Mediation exists when "the effects of stimuli on behaviour are mediated by various transformation processes internal to the organism" (Baron and Kenny, 1986, p.1176). The research posits that in the case of ISPs the effects of KM on CVR is mediated by GM. In other words, global mindset serves as the mechanism through which knowledge management enhances its effects on client-vendor relationships.

Following the upper echelon theory (Hambrick, 2007), this research argues that top management is ultimately responsible for the overall orientation of an organisation. TMTs have access to resources and capabilities which they allocate in order to optimise the outcomes for the organisation. In international ventures, we argue that the ultimate responsibility to properly allocate resources in managing knowledge and developing cultural and relational capital across different cultures and national boundaries rests with TMTs. In this respect, the extent of global mindset of top management greatly influences the overall international orientation of the organisation. Firms which carry activities in diverse cultural, political and institutional environments are usually supported by TMTs with well-developed global mindset (Levy et al., 2007; Nielsen and Nielsen, 2011).

TMTs have access to a vast array of knowledge from both internal and external sources such as universities, consulting firms and industry associations and client (Chadee and Raman, 2012; Segelod and Jordan, 2004). This research argues that managing such knowledge by itself only has limited effects on CVR. Rather it is the ability of managers to properly evaluate and utilise the available stock of the firm's complex knowledge which leads to higher quality clientvendor relationship. Managers with well-developed global mindsets are better equipped to strategically evaluate the relevance of all available knowledge and their potential benefits to the organisation. TMTs with well-developed global mindsets also tend to have intercultural empathy, interpersonal impact and diplomacy (Javidan and Bowen, 2013), all of which contribute to the development and maintenance of high quality client-vendor relationships due to their capabilities to properly assess and interpret knowledge about markets and clients, manage ambiguity and uncertainty and work effectively across cultures and countries. This leads to the following hypothesis,

$H_{4}$ : The global mindset (GM) of TMTs mediates the relationship between knowledge management (KM) and the quality of client-vendor relationship (CVR). 
The hypothesized relationships in Figure 1 show the direct effect of KM on CVR $\left(\mathrm{H}_{1}\right)$ as well as the indirect effect through $\mathrm{GM}\left(\mathrm{H}_{2}+\mathrm{H}_{3}\right)$. Figure 1 postulates that knowledge management enhances the quality of client-vendor relationship directly $\left(\mathrm{H}_{1}\right)$ but also suggests that this effect is mediated by GM. In testing the hypotheses, the model also controls for the effects of business experience and firm size. Older ISPs are likely to be more experienced and have more developed knowledge management infrastructures in place which can enhance CVR. Similarly, firm size can influence CVR on the ground that larger firms have more resources to manage knowledge and develop the global mindset of their TMTs, which together results in better CVR.

**Figure 1 about here ${ }^{* *}$

\section{Methodology}

\section{Sample and data collection}

The research is based on a quantitative research design in order to test hypotheses $\mathrm{H}_{1}$ to $\mathrm{H}_{4}$ by using data from a survey of ISPs in India and the partial least squares (PLS) model estimation techniques. PLS has been used extensively in knowledge management research (for a recent application see: Leal-Millan et al., 2016). The survey of ISPs was conducted with the collaboration of the National Association of Software and Services Companies (Nasscom), the peak industry trade body of ISPs in India. Nasscom members account for more than $95 \%$ of the services outsourcing sector's revenue of approximately $\$ 146$ billion in 2015 with about two thirds being from global clients (Nasscom, 2013; 2015). The ISPs in the sample are knowledgeintensive, technology-based organisations which provide a range of customised IT supported services such as software development, payroll services, business process solutions and so on to clients worldwide.

An online questionnaire was developed and pre tested before being endorsed by Nasscom and mailed out to all members $(\mathrm{N}=842)$. The questionnaire was addressed to a member of the executive or top management team in each company i.e. top managers involved in strategic decision making. Following two reminders, a total of $68(8 \%)$ responses which were deemed complete and useable were retained for the purposes of analysis in this research. The relatively low response rate for online industry surveys is not unusual in an Asian country context where response rates of as low as less than 1\% for surveys has been reported (Roy and Berger 2005). India is also known to be a particularly challenging environment for researchers to collect data due to a general reluctance from businesses to disclose information (Raman et al., 2013). 
Despite its small size, the sample is fairly representative of the population in terms of age, but is somewhat over represented by larger firms in terms of number of size. About $60 \%$ of respondent are 10 years or younger and $67 \%$ has more than 200 employees.

\section{Measurement}

The main variables of interest are GM, KM and CVR. Global mindset (GM) is measured based on five items related to top managers' familiarity with global economic and cultural environments (Chadee et al., 2011; Levy et al., 2007; Story and Barbuto 2011). Knowledge management (KM) comprises six items relating to TMT's capability in acquiring, assessing and utilising complex knowledge from varied sources for the benefit of the organisation (Chadee and Raman, 2012; Kianto et al., 2016). Client-vendor relationship quality (CVR) consists of four items describing the level of trust, commitment, business understanding and conflict management between vendors and their clients (Lee, 2001). All the variable items are presented in Table 1. The study also uses two control variables which are common in this type of research; business experience and firm size (Lahiri and Kedia, 2011). For this study, experience is measured as number of years in business and size is measured by number of employees.

\section{Common method variance}

The threat of common method variance (CMV) exists when perceptual data on both the dependent and independent variables are collected from the same person at a point in time (Chang et al., 2010). In order to address the potential threat of CMV, we use both procedural and statistical remedies suggested by Podsakoff et al. (2003) and Chang et al. (2010). For example, we used different scale formats and endpoints. Moreover, the survey was anonymous to allow respondents to participate without any fear of social desirability. The study also used Herman's single factor test to assess the threat of CMV. Herman's single factor test indicates a lack of such threat if no single factor explains the majority of the variance. All items measuring the constructs were factor analysed using maximum likelihood technique with Varimax rotation. The results show that no single factor emerged and no factor accounted for more than $50 \%$ of the variance. Moreover, a complex model including mediation which is hard to visualise the respondents is also tested. Accordingly, it can be safely assumed that CMV is not a threat to the study findings. 


\section{Results and discussion}

This study tests hypotheses $\mathrm{H}_{1}$ to $\mathrm{H}_{4}$ using the partial-least squares (PLS) approach to structural equation modelling (SEM). PLS-based SEM is suitable when the sample size and the numbers of indicators and latent variables are not large enough for covariance-based modelling. The current study has met the guidelines in using PLS recommended by Marcoulides and Saunders (2006) in terms of PLS estimation after taking into account the main objective of the study (i.e., estimating relationships rather than predictive modelling), the sample size of 68 firms, 15 indicators, 3 latent variables, factor loadings (minimum of .70), and factor inter-correlations (minimum of .42) in order to develop and test a PLS-based structural model with acceptable statistical power.

Before undertaking the path analysis, a confirmatory factor analysis (CFA) was performed on all of the constructs in order to examine the homogeneity and consistency of items comprising each construct and construct validity. Details of the CFA (Table 1) show that all of the items measuring each of the three constructs loaded highly on the pre-determined factors.

\section{**Table 1 about here**}

The measurement model fits the data well, as shown by the statistically significant loadings of items in their corresponding constructs at $\mathrm{p}<.05$, which indicates the convergent validity of the constructs. The cross-loadings of items in other constructs are much lower than the predetermined loadings. The values of Cronbach's $\alpha$ and composite reliability coefficients were all above the minimum threshold of .70, which indicates item homogeneity, consistency, scale reliability and construct validity (Bagozzi et al., 1991; Kock, 2012). The full collinearity variance inflation factors are lower than the maximum tolerable value of 5 (Hair et al., 2010) which suggest that multicollinearity is not an issue in the measurement model.

Table 2 shows the means, standard deviation and correlations of the five variables used in the succeeding analysis of the structural model-data fit. The bold figures are the square root values of the AVEs of each construct, which are higher than the correlation coefficient values of each construct relative to other constructs, which indicates the constructs' discriminant validity (Bagozzi et al., 1991). Overall, the results of the test of the measurement model-data fit suggested that the constructs used in this study have satisfactory levels of construct validity, internal consistency (i.e., reliability), and convergent as well as discriminant validity. 
After undertaking CFA, the structural models are developed and tested in order to test hypotheses $\mathrm{H}_{1}-\mathrm{H}_{4}$. Two nested structural models were developed and tested on mediation analysis. Testing of these models is necessary to determine whether GM mediates the effects of $\mathrm{KM}$ on CVR and, if it does, whether there is partial or full mediation (Anderson and Gerbing, 1988; James and Brett, 1984).

The various path coefficients are summarised in Table 3 and Figure 2. The first model (Model A) shows a fully-mediated model whereby GM fully mediates the effects of KM on CVR. The second model (Model B) is a partially-mediated model whereby GM partially mediates the relationships between KM and CVR. This model suggests that there are other direct effects of KM on CVR which cannot be accounted for by GM.

$$
\begin{aligned}
& * * \text { Table } 3 \text { about here }{ }^{* *} \\
& \text { **Figure } 2 \text { about here }
\end{aligned}
$$

A comparison of, the fully mediated and partially mediated models shows that Model B has higher average r-squared (ARS) value relative to Model A which suggests that the former has accounted for exogenous variables with higher predictive power in terms of explaining the variations in the endogenous variables (Kock, 2012). Model B also has higher goodness-of-fit (GoF) global index (Amato et al., 2004) which represents the overall quality of the model. These results suggest that the partial mediation model (i.e. Model B) has a better predictive quality relative to the full-mediation model (i.e. Model A). A test of the significance of the indirect effects in Model B based on the recommendation of Preacher and Hayes (2008) was also undertaken. The results show that the direct effects (i.e., KM $\rightarrow$ CVR), the indirect (i.e., $\mathrm{KM} \rightarrow \mathrm{GM} \rightarrow \mathrm{CVR}$ ) and total effects (i.e., $\sum$ direct and indirect effects) are significant. The indirect effect has an effect size of .11 (Cohen, 1992) which suggests that the indirect effects are substantially relevant in explaining the partial mediating role of GM in the KM-CVR linkages. Based on the foregoing results, Model B has a better predictive quality than Model A.

The results show that KM has a positive and statistically significant effects on CVR, thereby supporting $\mathrm{H}_{1}$. The direct effects of KM on GM are also positive and significant with large effect size which supports $\mathrm{H}_{2}$. The relationship between GM and CVR is also positive and statistically-significant with large effect size, hence supporting $\mathrm{H}_{3}$. The results also suggest that 
GM partially and substantively mediates the relationship between $\mathrm{KM}$ and CVR $\left(\mathrm{H}_{4}\right)$. In Model B, KM was statistically-significant in explaining $19 \%$ of the variations (i.e., $r^{2}$ ) in the firms' level of GM. On the other hand, GM along with KM, experience and firm age, explained 40\% of the variations in the firms' CVR. The Stone-Geisser $\mathrm{Q}^{2}$ is a measure of the predictive quality of the proposed model (Geisser, 1975; Stone, 1974). A $Q^{2}$ value greater than zero suggests the model has acceptable predictive validity. In Model B, the $\mathrm{Q}^{2}$ is .42 for CVR and .19 for GM, which further supports the hypotheses of the study. Both control variables, firm size and business experience, have insignificant effects on CVR.

The overall results provide empirical support towards the original contention that while knowledge management contributes positively towards client-vendor relationship quality, for ISPs global mindset constitutes a critical factor in enhancing client-vendor relationship quality. The results show clearly that global mindset plays an important mediating role of the effects of knowledge management on client-vendor relationship quality. In other words, global mindset explains the relationship between knowledge management and client-vendor relationship quality.

The international client base of ISPs means that the capability to deal effectively with employees and clients from diverse cultural and ethnic backgrounds and the ability to communicate in different languages can be an asset in transforming tacit knowledge from clients into better client-vendor relationship quality. Client-vendor relationship quality also depends on trust, respect and commitment, all of which could be enhanced through superior understanding of clients' values, language and cultures.

Well-developed global mindsets provide TMTs with superior knowledge of the broader business environments of their clients, beyond simply the legal, political and economic environments. This finding is significant for ISPs in general because global mindset has the potential to act as a dynamic capability (Teece, 2014) which ISPs can develop and deploy in order to optimise their client-vendor relationship quality. The results are also significant for client firms given that their performances are intertwined with those of their clients.

\section{Conclusion}

Research on client-vendor relationship management in the context of international service providers remains underdeveloped. This is despite the fact that the last decade has experienced rapid growth in ISPs, particularly from emerging economies such as Brazil, Russia, India and 
China (Klafke et al., 2016). Furthermore, ISPs operate in diverse and complex environments and often have to deal with multiple languages, cultures, and general business environments at any given time. ISPs enter projects with knowledge and people only to become integral parts of their clients' businesses such that their failures and successes are intertwined. ISPs work closely with their clients in the design and delivery of highly specialised and customised services on a global scale. The nature of the services rendered by ISPs means that they rely on their clients to gain deep knowledge of their business, resources and future needs. Clients possess valuable tacit knowledge of their businesses, the sharing of which with ISPs become critical for the successful delivery of customised services which meet clients' needs. In this respect, the capability of ISPs in managing knowledge is critical in ensuring their success. Thus, an interesting question arises as to how ISPs, particularly those from emerging economies which operate in diverse global business environments, can manage knowledge effectively in order to enhance their CVR?

The research draws from the experience of a sample of ISPs from India to show that in an increasingly globalised world, global mindset serves as the mechanism which allows top managers to transform various forms of knowledge into better quality partnerships. While both KM and GM have been found to separately influence relationship quality (Lee, 2001; Raman et al., 2013), this study finds that by itself KM only has limited effects on developing CVR. The results show that GM of top managers plays an important role in enhancing the effects of effective knowledge management on the quality of client-vendor relationships. The significant mediation effect of GM on the association between KM and CVR also highlights the importance of both global intellectual capital (GIC) and global social capital (GSC) (Javidan and Bowen, 2013) as integral elements of global mindset. Managers with GIC have the cognitive skills to evaluate vast amounts of complex information for informed decision making in a global context. Those with GSC have the psychological skills to develop trusted relationships and are comfortable in working with people across functions, cultures and countries.

The findings from this research have three main implications. Firstly, the positive effects of both KM and GM on CVR suggest that by strengthening KM and GM, ISPs can enhance the quality of CVR relative to their competitors. The interplay between KM and GM further highlights that GM is critically important in enhancing CVR. This finding is particularly relevant in an environment where ISPs are becoming increasingly global in their business orientations. Globally oriented top managers are likely to be more effective in assessing global 
risks and sensing global business environmental changes (Javidan and Bowen, 2013; Story and Barbuto, 2011). Thus, professional development programs which are designed to improve the overall global mindset of top management teams should lead to better quality client-vendor relationships.

Secondly, the findings provide valuable guidance to ISPs from developing countries that GM constitute a valuable tool in enhancing CVR. Firms from a number of emerging economies in Asia, such as China, the Philippines, Malaysia and Indonesia are also gradually entering the global IT services sector and aspiring to become significant players in this sector. These firms can potentially learn from the experience of Indian ISPs in enhancing their client-vendor relationships by developing the GM of their TMTs.

Lastly, the findings provide further evidence for emerging economy ISPs that employees with well-developed global mindsets constitute valuable and rare resources capable of conferring competitive advantage to the organisation. The challenge for ISPs, particularly those from emerging and developing countries, is how to retain such employees in an increasingly competitive labour market where a global shortage of skilled IT professionals has unleashed "the war for talent" (Ray et al., 2012)

As with most research, this study has several limitations and as such, the findings need to be interpreted with caution. The first limitation is the relatively small sample size due largely to the challenges of collecting primary data in India. The small sample size limits the generalisability of the results and also constrained the modelling exercise of this research. A second limitation relates to the fact that the data used for hypothesis testing is from a single industry and single country. This further limits generalisation as the institutional environment differs significantly in different countries; particularly in developing countries. A third limitation of the study relates to the measurement of client-vendor relationship quality. CVR is measured from one side (vendor side only) of the dyadic relationships between ISPs and their clients.

To enhance generalisability of the findings, future research could address some of the limitations above in a number of ways. Future research could improve the generalizability of the results by using a larger sample size, ideally drawn from different countries. The use of data from different countries would also allow analysis of how institutional differences impact on CVR. Another avenue for future research is in the conceptualisation and measurement of relationship quality at dyadic level. Developing and maintaining client-vendor relationships 
involve the development of mutual trust and commitment from both parties. The present research investigates the importance of GM in the development of CVR from the perspective of the service provider only. Future research could extend our understanding of CVR by extending the enquiry to the clients. 


\section{References}

Amato, S., Esposito-Vinzi, V. and Tenenhaus, M. (2004), "A global goodness-of-fit index for PLS structural equation modelling", in Oral Communication to PLS Club, HEC School of Management, France.

Anderson, J. and Gerbing, D.W. (1988), "Structural equations modelling in practice: a review and recommended two step approach", Psychological bulletin, Vol. 103 No. 3, pp. 411-423.

Ata, U.Z. and Toker, A. (2012), "The effect of customer relationship management adoption in business-to-business markets", Journal of Business \& Industrial Marketing, Vol. 27 No. 6, pp. 497-507.

Bagozzi, R., Yi, Y. and Phillips, L. (1991), "Assesing construct validity in organisatioal research", Administration Science Quarterly, Vol. 36 No. 3, pp. 421-458.

Barney, J., Wright, M. and Ketchen Jr., D.J. (2001), "The resource-based view of the firm: ten years after 1991.", Journal of Management, Vol. 27 No. 6, pp. 625 - 641.

Baron, R.M. and Kenny, D.A. (1986), "The moderator-mediator variable distinction in social psychological research: conceptual, strategic, and statistical considerations", Journal of Personality and Social Psychology, Vol. 51 No. 6, pp. 1173-1182.

Chadee, D. and Raman, R. (2012), "External knowledge and performance of offshore IT service providers in India: the mediating role of talent management", Asia Pacific Journal of Human Resources, No. 50, pp. 459-482.

Chadee, D., Raman, R. and Michailova, S. (2011), "Sources of competitiveness of offshore IT service providers in India: towards a conceptual model", Competition \& Change, Vol. 15 No. 3, pp. 196-220.

Chang, S.-J., Witteloostuijn, A.v. and Eden, L. (2010), "From the editors: common method variance in international business research", Journal of International Business Studies, Vol. 41 No. 2, pp. 178-84.

Cohen, J. (1992), "A power primer", Psychological bulletin, Vol. 112 No. 1, pp. 155-159.

Denk, N., Kaufmann, L. and Roesch, J.-F. (2012), "Liabilities of foreignness revisited: a review of contemporary studies and recommendations for future research", Journal of International Management, Vol. 18 No. 4, pp. 322-334.

Dyer, J.H. and Singh, H. (1998), "The relational view: cooperative strategy and sources of interorganizational competitive advantage", The Academy of Management Review, Vol. 23 No. 4, pp. 660-679.

Enlow, S. and Ertel, D. (2006), "Achieving outsourcing success: efective relationship management", Compensation \& Benefits Review, Vol. 38 No. 3, pp. 50-55.

Geisser, S. (1975), "The predictive sample reuse method with applications", Journal of the American Statistical Association, Vol. 70 No. 350, pp. 320-328.

Grant, R.M. (1996), "Toward a knowledge - based theory of the firm", Strategic Management Journal, Vol. 17 No. Winter Special Issue, pp. 109-122.

Hair, J.F., Black, W.C., Babin, B.J. and Anderson, R.E. (2010), Multivariate Data Analysis: A Global Perspective, seventh ed., Pearson, New Jersey.

Hambrick, D.C. (2007), "Upper echelons theory: an update", The Academy of Management Review, Vol. 32 No. 2, pp. 334-343. 
Holzweber, M., Mattsson, J., Chadee, D. and Raman, R. (2012), "How dynamic capabilities drive performance in the Indian IT industry: the role of information and co-ordination", Service Industries Journal, Vol. 32 No. 4, pp. 531-550.

James, L.R. and Brett, J.M. (1984), "Mediators, moderators, and tests for mediation", Journal of applied psychology, Vol. 69 No. 2, pp. 307-321.

Javidan, M. and Bowen, D. (2013), "The 'global mindset' of managers: what is, why it matters, and how to develop it", Organizational Dynamics, Vol. 42, pp. 145-155.

Javidan, M. and Walker, J.L. (2012), "A whole new global mindset for leadership", People \& Strategy, Vol. 35 No. 2, pp. 36-41.

Kale, P., Singh, H. and Permutter, H. (2000), "Learning and protection of proprietary assets in strategic alliances: building relational capital", Strategic Management Journal, Vol. 21 No. 3, pp. 217-237.

Kedia, B.L. and Lahiri, S. (2007), "International outsourcing of services: a partnership model", Journal of International Management, Vol. 13 No. 1, pp. 22-37.

Kianto, A., Vanhala, M. and Heilmann, P. (2016), "The impact of knowledge management on job satisfaction", Journal of Knowledge Management, Vol. 20 No. 4. Retrieved from http://www.emeraldinsight.com/doi/pdfplus/10.1108/JKM-10-2015-0398

Klafke, R.V., Helmann, C.L., Picinim, C.T., Francisco, A.C.d. and Pilatti, L.A. (2016), "Primary knowledge management practices applied in Brazil, Russia, India and China (BRIC) industries from 2001 - 2010", Journal of Knowledge Management, Vol. 20 No. 4. Retrieved from http://www.emeraldinsight.com/doi/pdfplus/10.1108/JKM-12-2015-0522

Kock, N. (2012), WarpPLS3.0 User Manual, Script Warp Systems, Laredo, Texas.

Kogut, B. and Zander, U. (1992), "Knowledge of the firm, combinative capabilities, and the replication of technology", Organization Science, Vol. 3 No. 3, pp. 383-397.

Ku, E.C.S. and Fan, Y.W. (2009), "Knowledge sharing and customer relationship management in the travel service alliances", Total Quality Management \& Business Excellence, Vol. 20 No. 12, pp. 1407-1421.

Lahiri, S. and Kedia, B. (2009), "The effects of internal resources and partnership quality on firm performance: an examination of Indian BPO providers", Journal of International Management, Vol. 15 No. 2, pp. 209-224.

Lahiri, S. and Kedia, B.L. (2011), "Determining quality of business-to-business relationships: a study of Indian IT-enabled service providers", European Management Journal, Vol. 29 No. 1, pp. 11-24.

Leal-Millan, A., Roldan, J.L., Leal-Rodriguez, A.L. and Ortega-Gutierrez, J. (2016), "IT and relationship learning in networks as drivers of green innovation and customer capital: evidence from the automobile sector", Journal of Knowledge Management, Vol. 20 No. 3, pp. 444-464.

Lee, J.-N. (2001), "The impact of knowledge sharing, organizational capability and partnership quality on IS outsourcing success", Information \& Management, Vol. 38 No. 5, pp. 323-335.

Levy, O., Beechler, S., Taylor, S. and Boyacigiller, N.A. (2007), "What we talk about when we talk about 'global mindset': managerial cognition in multinational corporations", Journal of International Business Studies, Vol. 38 No. 2, pp. 231-258.

Lin, H.-F. (2015), "Linking knowledge management orientation to balanced scorecard outcomes", Journal of Knowledge Management, Vol. 19 No. 6, pp. 1224-1249. 
Marcoulides, G.A. and Saunders, C. (2006), "PLS: a silver bullet?", MIS quarterly, Vol. 30 No. 2, pp. 3-9.

Mathews, J. (2006), "Dragon multinationals: new players in 21st century globalization", Asia Pacific Journal of Management, Vol. 23 No. 1, pp. 5-27.

Nardon, L. and Steers, R.M. (2008), "The new global manager: learning cultures on the fly", Organizational Dynamics, Vol. 37 No. 1, pp. 47-59.

Nasscom. (2013), "The IT-BPO secor in India: strategic review", National Association of Software and Service Comapnies, New Delhi.

Nasscom. (2015), "Annual report 2014-15", National Association of Software and Service Comapnies, New Delhi.

Nielsen, B. and Nielsen, S. (2011), "The role of top management team international orientation in international strategic decision-making: the choice of foreign entry mode", Journal of World Business, Vol. 46 No. 2, pp. 185-193.

Peng, M.W., Sunny Li, S., Pinkham, B. and Hao, C. (2009), "The institution-based view as a third leg for a strategy tripod", Academy of Management Perspectives, Vol. 23 No. 3, pp. 6381 .

Podsakoff, P.M., macKenzie, S.B. and Lee, J.-Y. (2003), "Common method bias in behavioral research: a critical review of the literature and recommended remedies", Journal of applied psychology, Vol. 88 No. 5, pp. 879-903.

Preacher, K.J. and Hayes, A.F. (2008), "Asymptotic and resampling strategies for assessing and comparing indirect effects in multiple mediator models", Behavioural Research Methods, Vol. 40 No. 3, pp. 879-891.

Ramachandran, J. and Pant, A. (2010), "The liability of origin: an emerging economy perspective on the costs of doing business abroad", in Divinney, T.M., Pedersen, T. and Tihanyi, L. (Eds.), Advances in International Management: The Past, Present and Future of International Business and Management, Emerald, New York, pp. 1 - 58.

Raman, R., Chadee, D., Roxas, B. and Michailova, S. (2013), "Effects of partnership quality, talent management, and global mindset on performance of offshore IT service providers in India", Journal of International Management, Vol. 19 No. 4, pp. 333-346.

Ray, R.L., Mitchell, C., Abel, A.L. and Phillips, P. (2012), "Why the human capital function still has far to go", in Kerr, J. and Toriello, M. (Eds.), McKinsey \& Company.

Roy, A. and Berger, P.D. (2005), "E-mail and mixed mode database surveys revisited: exploratory analyses of factors affecting response rates", Journal of Database Marketing \& Customer Strategy Management, Vol. 12 No. 2, pp. 153-171.

Segelod, E. and Jordan, G. (2004), "The use and importance of external sources of knowledge in the software development process", $R \&$ D Management, Vol. 34 No. 3, pp. 239-252.

Stone, M. (1974), "Cross-validatory choice and assessment of statistical predictions", Journal of the Royal Statistical Society, Vol. 36 No. 1, pp. 111-147.

Story, J.S.P. and Barbuto, J.E. (2011), "Global mindset: a construct clarification and framework", Journal of Leadership \& Organizational Studies, Vol. 18 No. 3, pp. 377-384.

Story, J.S.P., Barbuto Jr, J.E., Luthans, F. and Bovaird, J.A. (2014), "Meeting the challenges of effective international HRM: analysis of the antecedents of global mindset", Human Resource Management, Vol. 53 No. 1, pp. 131-155. 
Teece, D.J. (2014), "A dynamic capabilities-based entrepreneurial theory of the multinational enterprise", Journal of International Business Studies, Vol. 45 No. 1, pp. 8-37.

Tseng, S.-M. (2014), "The impact of knowledge management capabilities and supplier relationship management on corporate performance", International Journal of Production Economics, Vol. 154, pp. 39-47.

Wang, C. and Han, Y. (2011), "Linking properties of knowledge with innovation performance: the moderate role of absorptive capacity", Journal of Knowledge Management, Vol. 15 No. 5, pp. 802-819.

Winkler, J., Dibbern, J. and Heinzl, A. (2008), "The impact of cultural differences in offshore outsourcing: case study results from German-Indian application development projects", Information Systems Frontiers, Vol. 10 No. 2, pp. 243-258.

Yu, Y. and Sharma, R.R. (2016), "Dancing with the stars: what do foreign firms get from highstatus local partners?", Management Decision, Vol. 54 No. 6. Retrieved from:

http://www.emeraldinsight.com/doi/pdfplus/10.1108/00251740210441036

Zack, M., McKeen, J. and Singh, S. (2009), "Knowledge management and organizational performance: an exploratory analysis", Journal of Knowledge Management, Vol. 13 No. 6, pp. 392-409.

Zeithaml, V., Parasuraman, A. and Berry, L.L. (1985), "Problems and strategies in services marketing", Journal of Marketing, Vol. 49 No. 2, pp. 33-46. 